\title{
The Making of Mental Health Counselors
}

ChaRmian ELKES, M.D., GHISLAINe D. GODENNE, M.D., and ANTHONY R. STONE, Ph.D.

The authors, all of whom are associate professors of psychiatry, are with the Henry Phipps Psychiatric Clinic, Department of Psychiatry and Behavioral Sciences, the Johns Hopkins Hospital, the Johns Hopkins University School of Medicine, Baltimore, $M d$. Tearsheet requests to Dr. Charmian Elkes, Johns Hopkins Hospital, Baltimore, Md. 21205.

Tapping and developing appropriate human qualities for psychotherapeutic application need not be limited to training for established professional mental health practitioners. Rather, we believe the "work test" of successful survival and creative development through the middle years of life often provides a genuine source of learned traits which may be applied in psychiatric treatment.

"Mental health counselors" is the title we apply to a group of mature women who have been trained to work as psychotherapists in psychiatrically supervised clinical settings. Most of them had no previous training in psychosocial fields. Since their training has been narrowly focused on acquiring the skills of individual and group psychotherapy, they are not expected to have the range of skills of psychiatrists, psychologists, or social workers. Such women are specifically equipped to work in mental health clinics or centers, always with psychiatric guidance. We shall describe the education and training that prepared them for such work.

In September 1966, a program for training selected women between 35 and 50 years of age was inaugurated in the Department of Psychiatry and Behavioral Sciences at the Johns Hopkins Hospital in Baltimore, Md. The program carried through 2 academic years and produced seven mental health counselors. It was meshed within the framework of existing psychiatric services. The major emphasis was on supervised work with patients and members of the patients' families, who presented the gamut of maladaptive psychosocial 
syndromes. Minor emphasis was on didactic learning, discussions, seminars, or conferences, which were selected and assigned for their practical value. No formal lectures or courses were offered, and theoretical instruction was not introduced until the second semester of the first year. Throughout the program, trainees were exposed to teachers and supervisors who had a variety of theoretical backgrounds and of convictions concerning the methods of conducting psychotherapy, some of which were conflicting. Such exposure, we believed, would help the trainees establish their own styles rather than follow rule-of-thumb methods.

The success of the program has been sufficiently validated empirically to encourage launching a second one. The second program, which began in September 1968, followed fairly closely the format of the first. We hope that our report will encourage other institutions to establish similar training programs to help alleviate the shortage of mental health workers. The third program was started in 1970, and it is planned to accept a new group of trainees every other year.

\section{History of Project}

The Johns Hopkins Hospital program was modeled after the pilot project in training mental health counselors, which was conducted at the National Institute of Mental Health from 1960 through 1962 under the direction of Dr. Margaret Rioch and Dr. Charmian Elkes (1). Articles concerning the program have appeared in both the professional literature (2) and the lay press. Interest, much of it supportive, was aroused in the mental health professions, although certain members of the various established mental health disciplines raised objections. For example, there were arguments that these women should be recruited for established curriculums in social work, psychology, nursing, and so forth. Positive or negative, however, it could not be denied that the pilot project was unusual. And it was attractive enough to prompt the Maryland State Conference on Social Welfare to study the possibility of starting a training program in Baltimore.

Dr. Godenne was asked to explore the matter. Conferences with Rioch and Charmian Elkes resulted in a proposal for a grant from the National Institute of Mental Health to support a program in the Baltimore area. This proposal was submitted in 1965 and shortly afterward denied on the basis that such a program would no longer be a "pilot project." And since there was as yet no category to qualify it for a training grant, no funds were available through the usual channels. If such a program were to be instituted, it would have to be selfsupporting.
Thus, within this stark limitation, a decision to make an attempt or pass the program by had to be made. The consensus among interested faculty members of the department of psychiatry and behavioral sciences was that we were willing to try. Dr. Joel Elkes, chairman of the department, therefore appointed a committee to organize a hospital-based training program for mental health counselors to operate within his department. The committee consisted of Godenne, chairman of the faculty committee, Dr. Anthony R. Stone, and Charmian Elkes.

When the program had been sufficiently outlined, the board of trustees of the Johns Hopkins Hospital provided official approval in early January 1966. The self-supporting proviso unfortunately necessitated high tuition fees for the trainees. Also, we assumed that a part-time administrative assistant would be needed and searched for such a person. Thus, to provide tape recorders and tapes for the program and at the same time offer the administrative assistant a modest salary, tuition levels for that first year were set at $\$ 850$ per trainee.

At the last minute, however, circumstances beyond her control prevented the administrative assistant from joining us. Another person was employed later in the semester, but because of her late arrival, the completely unique program to be coordinated, and some other factors, she did not remain. After her departure, the trainees were assigned their own coordinating tasks, and the program was completed in that manner. One disguised blessing was the opportunity thereby afforded to reduce the annual tuition to $\$ 400$ the second academic year. It remained at this figure for the succeeding program.

The teaching principles applied in our program paralleled those of the National Institute of Mental Health pilot project. Foremost was the principle that the training should primarily focus on practical experience and that theoretical instruction should play a minor role. Second, with the idea that there is no one right way to do therapy, the trainees were exposed to a variety of teachers with differing backgrounds and methods of working so that they would be encouraged to establish their own styles and spheres of interest. The Johns Hopkins trainees were also similar to the National Institute of Mental Health group in age and in educational and social background. There were, however, some differences in the two programs. The major one was that the department of psychiatry in a busy training and service hospital provides a wealth of patients and a variety of clinical experiences not available in a research hospital.

Over the 2 years, the trainees were supervised, on the average, about 1 hour for every 2 hours of 
treatment they offered. In retrospect, we sometimes question whether the training requirements or our own anxiety dictated such close supervision.

\section{Applicants for the Program}

After the Johns Hopkins Hospital approved the program, letters were sent to various alumnae groups and churches in the Baltimore area inviting applications. Godenne, during several talks in the area, also described the program and invited applicants. Additionally, all of us connected with the program talked about it informally at various social gatherings.

But the major stimulus for applicants was a feature story in the Baltimore Sun, on February 2, 1966, which was entitled, "Role Offered Housewives in Psychiatry-Clinic Begins Training Mature Women as Therapists." It takes little imagination to grasp the consequences implicit in such an intriguing news item. After its appearance, more than 200 telephone calls tied up our lines for more than 2 days. More than 100 letters poured in through the mail. All other work was almost impossible, and every inquiry was handled as soon as possible. The registrar (receptionist) who took the telephone calls and the staff members who received letters responded with an explicit statement of the qualifications and tuition costs. It was a hectic, exciting time.

Each potential applicant was informed that a college degree (in any field) was highly desirable, that there should be no small children at home, and that she should be prepared to spend at least 30 hours a week outside the home for approximately 10 months for 2 academic years. If the applicant could meet these criteria, she was then asked to submit a 1,500-word autobiography giving her history plus some thoughts on how she had become the person she was. No other instructions concerning this task were offered, allowing much freedom to the writer.

Because of the high tuition rate, many eligible women were unable to apply. We hope that in the future some supporting funds will be forthcoming so that this distasteful qualification can be eliminated. The rationale for the other qualifications is fairly obvious, with the possible exception of the college degree. The rationale for that is less clear, especially if the applicant's field of study is apparently irrelevant to psychotherapy. Two of the trainees in our first class had not completed college. The title of mental health counselor now exists within the job descriptions of the State of Maryland's civil service, and a college degree is part of the qualification. Therefore, possession of a degree increases employment opportunities within the State system. In addition, we believe that completion of a prescribed course of study provides evidence of tenacity in the pursuit of goals, a quality considered crucial in our program. In fact, only women with a bachelor's degree or higher will be considered in the future.

By April 15, 1966, when applications were closed, 27 women had submitted their autobiographies. Sixteen applications that were received after the deadline were returned. The characteristics of the 27 applicants as revealed in their autobiographies are presented in table 1.

\section{Selection of Trainees}

A selection committee, consisting of the authors and one other faculty member, Dr. Lino Covi, assistant professor of psychiatry, invited all applicants who had submitted autobiographies to attend a group screening interview. The 27 women were subdivided into three groups, and each group met with the selection committee from 11 a.m. to 4 p.m. on three consecutive Wednesdays. The group screening consisted of the following steps:

1. Applicants were paired, and each was asked to introduce the other member of her pair.

2. The entire group was then asked to form a committee and present a plan for the first year of training of mental health counselors.

3. An informal discussion of the program took place during the lunch period.

4. A teaching phonograph record (Dr. Merton Gill, New Haven, Conn.) of an initial interview with a neurotic woman was played for the applicants, and they were asked to evaluate and discuss what they had heard.

5. Each applicant was asked what she would do if she were not selected.

6. Finally, each woman was asked to select two women within the group other than herself whom she believed would be good candidates for the training.

Nine candidates emerged as most likely for acceptance, and, interestingly, the selection committee reached a remarkable consensus concerning the acceptance or rejection of each of the 27 applicants. Also, candidates were excluded only by unanimous decision.

Since the program was planned for eight trainees, the nine acceptable candidates were asked to return for another selection session. This time, they were divided into three groups of three and, in turn, each trio interviewed a new adolescent patient selected from the evaluation list of the adolescent service. The interviews with each patient were conducted in a conference room equipped with a oneway mirror and microphone. During the interviews. 
Table 1. Characteristics of the 27 applicants for traineeships in mental health counseling

Characteristic

Total Accepted applicants applicants

Age group (years):

35-39

$40-44$

45-49..............

$50-54$

$55-59$

$60-64$

65-69...

Not stated . . . . . . . . . . .

Marital status:

Married. . . . . . . . . . . . .

Separated or divorced......

Widowed ................

Not stated

Children:

None

10

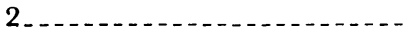

3

4

Not stated . . . . . . . . . . .

College education:

Degree.........

No degree.

Not stated . . . . . . . . . . . .

Psychiatric help, now or in past:

Yes....................

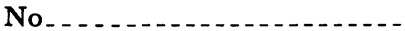

$\begin{array}{rl}5 & 3 \\ 5 & 3 \\ 5 & 2 \\ 5 & 1 \\ 1 & 0 \\ 1 & 0 \\ 1 & 0 \\ 4 & 0 \\ 18 & 8 \\ 4 & 1 \\ 3 & 0 \\ 2 & 0 \\ & \\ 1 & 0 \\ 3 & 1 \\ 7 & 3 \\ 5 & 2 \\ 5 & 2 \\ 6 & 1 \\ & \\ 20 & 6 \\ 4 & 2 \\ 3 & 1 \\ 14 & 6 \\ 13 & 3\end{array}$

those applicants not engaged joined the selection committee in the observation area to appraise the interaction between the patient and the interviewers. Later, all applicants were asked to give their impressions of what they had seen.

At the close of the final day of selection, the committee could not agree on whom to eliminate. Therefore, all nine candidates were accepted. Before the program began, however, one woman had to resign because of her family situation, fortuitously leaving us with the original number desired. One other trainee resigned late in the first semester, leaving us with seven. Table 1 presents the characteristics of the nine accepted candidates.

\section{Training Program}

The training program was launched as planned the week following Labor Day, in 1966. Candidates were paired and assigned offices in the adolescent psychiatry service. Convenience rather than theoretical formulation governed the decision to start the trainees with adolescent patients. Not only were the trainees' offices located in that service, but also Godenne had her office there. Each candidate was given two new patients to treat (an adolescent boy and girl), who had been evaluated by a senior staff member of the adolescent psychiatry service. The trainees were instructed to see their patients 1 hour weekly, and each woman was also assigned a supervisor with whom she met 1 hour a week. Tape recordings and rather complete notes were required for every interview. In case of an emergency or if a supervisor could not be reached, a staff psychiatrist was assigned for emergency consultation each weekday.

As a group, the women were requested to attend weekly group dynamics meetings with Dr. Garrett O'Connor, assistant professor of psychiatry, a weekly group supervision session with Charmian Elkes, and a weekly open discussion conference with Godenne. Also, during their first few weeks, the trainees were required to sit in on interviews of clinic patients which were conducted by members of the staff of the adolescent psychiatry service. Optional activities to which the women were invited included weekly case conferences at the adolescent psychiatry service and the Henry Phipps Psychiatric Clinic, plus a weekly research seminar, which they were encouraged to attend selectively as topics appealed to them. When it seemed appropriate to their training, the trainees were invited to the year 5 (senior year) medical-student conferences and public school case seminars. Observation by the women of group psychotherapy began in their second week of training.

After 2 months in the adolescent psychiatry service the trainees were paired, and each pair was assigned an evaluation of a new patient. After spending about 2 hours with the patient in the clinic, the trainees conferred with the family and visited the home and school. Then they discussed their experiences and observations in detail with Godenne.

By January 1967, each mental health counselor trainee was allowed to take on two more adolescent patients, and, by April 1967, each woman was assigned a patient from the child psychiatry service. Additional supervisors were also assigned to maintain close coverage and instruction.

During the trainees' first year, seminars by faculty members on various topics were also scheduled, ranging over the following subjects:

Psychological testing ( 2 sessions)

The family as a social system ( 4 sessions)

Developmental processes ( 4 sessions)

Mental hygiene

What is psychotherapy?

Family therapy

Group therapy

Adolescent problems

Problems in therapy

Child psychiatry

Schizophrenia

Psychosomatic medicine

To round off this rather full and variegated schedule, the women also were given opportunities 
to observe and listen to interviews conducted by different staff members.

While the trainees' vacations were officially scheduled to coincide with those of the public schools, when the summer of 1967 arrived most trainees chose not to take the full summer recess. Rather, they continued with their patients and supervisors, taking at most a month's respite.

After the summer, the trainees, now in their second year, branched off in different services of the Henry Phipps Psychiatric Clinic. Patients from the adult outpatient department were assigned to all trainees, and their workload in the child psychiatry service was increased. Four women worked in the psychosomatic clinic; five, in the emergency treatment clinic; two, in the comprehensive care clinic; and three worked in the inpatient service-where all the trainees attended meetings. Two of the trainees treated inpatients directly; three served as co-therapists in groups.

Each service provided the trainees supervision along with the assignments of patients. While the mental health counselors were asked not to carry more than 10 active cases at any one time, their total caseloads included family members, especially when the original patients were children or adolescents. Therefore the trainees' loads far exceeded 10 individual patients.

Other activities during the trainees' second year included a weekly reading seminar conducted by $\mathrm{Dr}$. Herzl Spiro, associate professor of psychiatry, and discussions on group processes offered biweekly by O'Connor. Elkes and Godenne continued their weekly meetings as in the first year. In addition, the trainees observed as Dr. John Sheehan, instructor in psychiatry, treated a long-term patient, holding his weekly sessions behind a one-way mirror. These sessions were followed by discussions concerning the patient, therapeutic processes, goals, prognosis, and the like. As part of their responsibilities in the adult out-patient department, the trainees also conducted routine evaluations in collaboration with senior staff members.

We consider the program successful and are encouraged by its acceptance at the Henry Phipps Psychiatric Clinic. The acceptance, however, was by no means universal at first; there was much skepticism and sardonic humor about the "housewives." Nevertheless, over the 2 years the staff gradually came to tolerate, and later to acquire great respect, for the mental health counselors' services. In the clinic, as outside of it, the professionals who have no personal knowledge of mental health counselors are generally the ones who express skepticism and hostility; those who work with these women by and large welcome them with respect and find their services useful.

The method of training actually fostered rather high anxiety among the trainees during the first year because of our refusal to provide didactic teaching. Because they were exposed to different theoretical viewpoints and observed different methods of conducting psychotherapy it was impossible for the trainees to latch on to a given set of rules, which would have made them feel much safer and more reassured. Often they were given conflicting opinions by different supervisors since a given patient might be presented to an individual supervisor as well as in group supervision and in case conferences. This variety caused confusion at first but resulted eventually in the trainees having a healthy skeptical attitude about dogmatic statements and also enhanced their ability to listen with an open mind to varying points of view.

Table 2 summarizes the patient load handled by the mental health counselor trainees during their 2 years of training.

\section{Supervision}

Seventeen staff members (full-time and parttime) supervised the trainees, usually on a regular

Table 2. Individual therapy undertaken by mental health counselor trainees, by patients' sex and age groups

\begin{tabular}{|c|c|c|c|c|c|c|c|c|c|}
\hline Trainee's No. & $\begin{array}{c}\text { Total } \\
\text { number } \\
\text { patients }\end{array}$ & Male & Female & $1-13$ & $14-21$ & $\begin{array}{l}22 \text { and } \\
\text { over }\end{array}$ & $\begin{array}{c}\text { Total } \\
\text { number }\end{array}$ & $\begin{array}{c}\text { Range } \\
\text { per } \\
\text { patient }\end{array}$ & $\begin{array}{c}\text { Average } \\
\text { number } \\
\text { per patient }\end{array}$ \\
\hline $\begin{array}{l}1 \\
1 \\
2 \\
3 \\
4 \\
5 \\
6\end{array}$ & $\begin{array}{l}15 \\
21 \\
32 \\
37 \\
14 \\
17 \\
24\end{array}$ & $\begin{array}{r}6 \\
9 \\
10 \\
14 \\
5 \\
6 \\
9\end{array}$ & $\begin{array}{r}9 \\
12 \\
22 \\
23 \\
9 \\
11 \\
15\end{array}$ & $\begin{array}{l}3 \\
1 \\
2 \\
1 \\
1 \\
4 \\
1\end{array}$ & $\begin{array}{r}5 \\
8 \\
10 \\
8 \\
5 \\
5 \\
13\end{array}$ & $\begin{array}{r}7 \\
12 \\
20 \\
28 \\
8 \\
8 \\
10\end{array}$ & $\begin{array}{l}310 \\
443 \\
421 \\
402 \\
348 \\
352 \\
384\end{array}$ & $\begin{array}{c}3-50 \\
1-67 \\
1-36 \\
1-41 \\
15-34 \\
1-107 \\
1-65\end{array}$ & $\begin{array}{l}20.9 \\
21.0 \\
13.0 \\
10.8 \\
24.8 \\
20.7 \\
16.0\end{array}$ \\
\hline
\end{tabular}


basis. The trainees, as well as having regular meetings with their supervisors, also knew that they could call on us in a crisis.

Individual supervision per trainee was as follows:

$\begin{array}{lcc}\text { Trainee's number } & \begin{array}{c}\text { Number of } \\ \text { hours }\end{array} & \begin{array}{c}\text { Number of } \\ \text { supervisors }\end{array} \\ 1 & 162 & 5 \\ 2 & 188 & 9 \\ 4 & 206 & 8 \\ 5 & 311 & 12 \\ 6 & 135 & 5 \\ & 79 & 8\end{array}$

The number of hours of supervision per hours of therapy given by the trainees may seem high over the whole program. Yet, despite the emphasis in the program on supervision, the staff time needed was not as great as indicated. Supervision was lavish to begin with, but it was reduced as the trainees became more experienced. Also, much group supervision was done, a method which has been found to be effective and to save staff time. After graduation, the mental health counselors generally had 1 hour a week of individual supervision and one weekly group supervision period of $1 \frac{1}{2}$ hours.

\section{Evaluation}

An attempt was made to evaluate the program in three ways. In January 1968, all supervisors who had participated in the program were invited to a meeting to discuss and exchange views about the trainees. Fifteen supervisors attended, and two sent written reports. We did not ask the supervisors to attempt to grade or rate ability. We only asked them to tell us how they believed the trainees functioned as therapists and how the trainees learned. We asked the supervisors if they would refer patients to the trainees. Although there were differences of opinion among the supervisors, each trainee was considered to be functioning well, to be capable of continuous learning, and was regarded by most of the supervisors who had known her to be a good person to whom to refer patients.

There were some very sharp differences of opinion. About one trainee, a supervisor said, "She should not work in a college because of her overidentification with adolescents." But another supervisor reported "She is particularly skilled in working with adolescents." Most of the differences, however, occurred between supervisors who had seen a trainee early in training, when anxiety was high and experience was low, and those who were currently seeing a trainee three-quarters of the way through the program, when she had begun to be more self-confident and sure in her position as a psychotherapist.

The large number of supervisors was important in two ways. First, it allowed the trainees to learn more from the supervisors with whom they had rapport, and second, concerning evaluation, individual judgments based either positively or negatively on personality reactions tended to be evened out.

For the second evaluation in April 1968, we invited three prominent Maryland psychiatrists outside of the Johns Hopkins Hospital to provide an opinion of the performance of the mental health counselors. They were Dr. James E. Carson, commissioner, State Department of Mental Hygiene (at that time, deputy commissioner) ; Dr. Virginia Huffer, associate professor of psychiatry, Psychiatric Institute, School of Medicine, University of Maryland; and Dr. Clarence G. Schulz, assistant medical director, Sheppard and Enoch Pratt Hospital, Towson. As a group, the three met with each mental health counselor in turn for about 45 minutes to discuss with her a patient currently in treatment. The patient was selected by the trainee, who sent a written case report before the meeting. The three examiners gave their views of the program, based on their general impression of how the group worked with their patients and then provided a brief critique of each trainee.

Two of the three psychiatrists were favorably impressed and considered the work of the trainees on a level with skills of the better second-year psychiatric residents. One examiner, however, was mostly critical. He expressed the belief that the trainees focused almost exclusively on interpersonal conflicts and relied on "relationship" therapy, while failing to understand ego functions. He indicated that he thought the group was fairly sophisticated about neurotic processes but weak on concepts relating to psychosis.

A second psychiatrist agreed that the women seemed primarily aware of interpersonal difficulties rather than intrapsychic conflicts, but he expressed approval of their training, maturity, and understanding of people. The third psychiatrist was more enthusiastic, but also noted the dependence on the interpersonal rather than the intrapsychic approach. His reactions, however, were warmly approving. He found that the trainees spoke of patients as human beings rather than as cases. He thought they had an impressive ability to relate to others on a feeling level, using spontaneity and intuition, and he was pleased by their nonuse of psychodynamics and psychiatric jargon. This psychiatrist expressed the opinion that these qualities might arise from the women's age and life experience, but also that the qualities reflected the women's training and role expectation. He was impressed by the women's considerable understanding of their own emotional reactions. He said he would unhesitatingly refer patients to all of them. 
The attitudes of the trainees toward the parents of patients impressed the first and third examiners. The first stated, "I heard a uniform emphasis on what the parents did to these children ...., with very little emphasis on how the patient might be keeping it going or what he might have contributed to it, and so forth." The third said, "There was none of the tendency ... to reject family members and resistance to dealing with other meaningful groups."

The second and third examiners stressed the difficulty of evaluating the trainees in the examination situation. Several times they expressed the belief that a woman would be more competent in an ongoing therapy situation than during such an examination. They both also said that in their remarks about individual women they concentrated on the critical and did not repeat the positive reactions which were common to the whole group of trainees.

The program is being evaluated independently under NIMH grant No. MH 1 5551-01 by Dr. Eberhart $\mathrm{H}$. Uhlenhuth, associate professor of psychiatry, University of Chicago. Upon completion, the results of this evaluation will be published separately.

We evaluate the work of the trainees and interns continuously and hope to do so indefinitely. We have the highest regard for their abilities in the work for which they were trained. At the Henry Phipps Clinic, the trainees' abilities as psychotherapists and their talents for describing and presenting people who are having various problems are so highly regarded that their skills and experience tend to be overvalued. In particular, the women were not trained in evaluation and diagnostic techniques and had little exposure to psychosis or organic brain syndromes during the training period. However, during and after internship these and other skills are often greatly expanded by the women in their work situations.

\section{Employment}

After the women were awarded their official Johns Hopkins Hospital certificates stating that they had completed 2 years of training as mental health counselors, their services were eagerly sought by the various services throughout the hospital. Some women were also offered employment in other settings. After deliberation, we decided to afford all the trainees an opportunity to spend 1 more year in an internship in which their responsibilities would increase considerably, but they would always have supervisors nearby to assist them. All the graduates accepted this plan and were employed between 1968 and 1969, in various services throughout the hospital complex, at $\$ 7,000$ a year.

In fact, the internship extended to a second year, and interns worked in the Henry Phipps Psychiatric
Clinic, adolescent service, acute treatment clinic, pediatric psychiatry, and inpatient service of the Johns Hopkins Hospital and in the John F. Kennedy Institute for the Mentally and Physically Handicapped Child. One intern also was given a teaching appointment at the Community College of Baltimore. Since the training had been established as an ongoing program, the interns also participated in the supervision of new trainees.

Currently, the mental health counselors who had completed 2 years of internship are employed, at a beginning salary of $\$ 10,000$, as follows: four in the Johns Hopkins Hospital (two in the Phipps clinic, one in student mental health, and one in pediatric psychiatry), two at Columbia Hospital and Clinic, one in Sinai Hospital, one in the Community College of Baltimore, one in the Kennedy Institute, one in the Seton Institute, and two are employed by private psychiatrists. Some counselors have two places of employment. One counselor is also the coordinator for new trainees and interns. The teaching role of the graduates has become evident in their various areas of employment.

In December 1970 the Johns Hopkins University School of Medicine granted approval, in principle, of the establishment of a master's degree in mental health for graduates of this program.

\section{Conclusion}

Our aim has been, and continues to be, to train a small, select group of women to become effective psychotherapists in various settings. Their training is based on supervised "learning by doing," working with the wide variety of psychiatric patients available at the Department of Psychiatry and Behavioral Sciences of the Johns Hopkins Hospital. Because of the large number of patients our trainees saw over the 2-year period, they are probably more experienced and capable than other beginning therapists after 2 years of training, even though they emerge with no diagnostic skills. The teaching seems costly in terms of staff time, but we believe that this cost is justified by the quality of work the graduates are equipped to do.

\section{REFERENCES}

(1) U.S. Public Health Service: Pilot project in training mental health counselors. PHS Publication No. 1254. U.S. Government Printing Office, Washington, D.C., 1965.

(2) Rioch, M. J., et al.: National Institute of Mental Health pilot study in training mental health counselors. Amer J Orthopsychiat 33: 678-689, April 1963. 